\title{
Induction of Immune Unresponsiveness to Concordant Islet Xenografts by Intrahepatic Preimmunization and Transient Immunosuppression
}

\author{
John A. Goss, Edward H. Finke, M. Wayne Flye, and Paul E. Lacy \\ Departments of Surgery and Pathology, Washington University School of Medicine, St. Louis, Missouri 63110
}

\begin{abstract}
Streptozotocin-induced, diabetic mice (C57BL/6) were preimmunized by injecting 25 low temperature, cultured WistarFurth (WF) rat islets into the portal vein, and the recipients received one injection of mouse and rat antilymphocyte sera. 3 wk later, fresh WF islets were transplanted under the kidney capsule of the preimmunized recipients, and normoglycemia was maintained in all 13 recipients for $60 \mathrm{~d}$. Removal of the grafts at $60 \mathrm{~d}$ returned the mice to a diabetic state. Transplants of fresh WF islets under the kidney capsule without pretreatment of the recipients had a mean survival time of $16.5 \pm 2.5 \mathrm{~d}$. These findings demonstrate that immune unresponsiveness can be achieved across a concordant, islet xenograft barrier within 3 wk after intrahepatic preimmunization with a small number of donor rat islets and transient immunosuppression with antilymphocyte sera. (J. Clin. Invest. 1994. 93:1312-1314.) Key words: islet xenografts • antilymphocytic serum • preimmunization • islet transplants $\bullet$ experimental diabetes
\end{abstract}

\section{Introduction}

Several years ago, Lacy et al. (1-3) demonstrated that it was possible to achieve indefinite survival ( $>100 \mathrm{~d}$ ) of rat islet allografts and concordant islet xenografts (rat to mouse) by low temperature culture of the donor islets, a single injection of antilymphocyte serum (ALS), ${ }^{1}$ and implantation of the islets into the liver via the portal vein. Low temperature culture of the donor islets was used to diminish the number of passenger leukocytes that was required to achieve indefinite survival of the islets (4). Naji and his associates (5) have shown that intrathymic transplants of rat islet allografts and a single injection of rat ALS (RALS) would produce indefinite survival of rat islet allografts and induction of immune unresponsiveness. Recently, we compared the intrathymic, intrahepatic, and kid-

Address correspondence to Paul E. Lacy, M.D., Ph.D., Department of Pathology, Washington University School of Medicine, 660 South Euclid Avenue, St. Louis, MO 63110.

Received for publication 16 September 1993 and in revised form 10 November 1993.

1. Abbreviations used in this paper: ALS, antilymphocyte serum; KC, kidney capsule; MALS, mouse ALS; MST, mean survival time; RALS, rat ALS; WF, Wistar-Furth.

J. Clin. Invest.

(C) The American Society for Clinical Investigation, Inc.

0021-9738/94/03/1312/03 \$2.00

Volume 93, March 1994, 1312-1314 ney capsule ( $\mathrm{KC}$ ) sites for induction of immune unresponsiveness to rat islet xenografts in mice using low temperature cultured donor islets and a single injection of mouse ALS (MALS) and RALS (6). Immune unresponsiveness was not induced with the $\mathrm{KC}$ site, however, both the intrathymic and intrahepatic sites permitted the induction of immune unresponsiveness to the islet xenografts.

Intrahepatic transplants of human islet allografts have produced normoglycemia in immunosuppressed diabetic patients with kidney transplants using partially purified (80-90\%) islet preparations $(7,8)$. Achievement of indefinite survival and induction of immune unresponsiveness in rodent models have used pure, hand-picked islet preparations, using special procedures to eliminate contaminating lymph nodes, acinar tissue, and ducts from the final preparation. Obviously, hand-picked islets could not be used for human islet allografts since $500,000-800,000$ islets are required to achieve normoglycemia. Thus, this study was undertaken to determine whether intrahepatic preimmunization with a small number of low temperature, cultured rat islets and a single injection of MALS and RALS into diabetic mice would prevent the rejection of a subsequent transplant of unaltered islets without additional immunosuppression. If this could be accomplished, then it would raise the possibility of using this approach for human islet allografts since a few thousand pure human islets could be handpicked and used for preimmunization.

\section{Methods}

Animals. Male Wistar-Furth (RT1 ${ }^{\text {u }}$ (WF) rats (Harlan Sprague Dawley, Inc., Indianapolis, IN) at 6-8 wk of age were used as pancreatic islet donors. Male C57BL/6 $\left(\mathrm{H}-2^{\mathrm{b}}\right)$ mice, 6-8 wk of age, were made diabetic by the intravenous injection of streptozotocin $(167 \mathrm{mg} / \mathrm{kg}$ body wt) (Upjohn Co., Kalamazoo, MI) via the tail vein. Only mice with nonfasting plasma glucose concentrations $>400 \mathrm{mg} \%$ were used as recipients.

Islet isolation. Pancreatic islets were isolated from the donor rats by the collagenase technique described previously $(9,10)$ and separated by centrifugation on a Ficoll gradient (11). Individual islets, free of attached acinar, vascular, and ductal tissue, were selected and removed with a Pasteur pipette with the aid of a dissecting microscope. The selected islets were then examined again under a dissecting microscope using a reflected green light for illumination to permit identification and removal of small lymph nodes that are occasionally present in the preparation (12). The hand-picked islets were either cultured overnight at $37^{\circ}$ before $\mathrm{KC}$ transplantation or were cultured in vitro at $24^{\circ} \mathrm{C}$ for $7 \mathrm{~d}$ before intrahepatic preimmunization in a humidified atmosphere of $95 \%$ air and $5 \% \mathrm{CO}_{2}$. The islets were cultured in CMRL1066 (Gibco Laboratories, Grand Island, NY) tissue culture medium containing $10 \% \mathrm{FCS}$, penicillin ( $100 \mathrm{U} / \mathrm{ml})$, streptomycin sulfate ( 100 $\mu \mathrm{g} / \mathrm{ml})$, D-glucose $(1.5 \mathrm{mg} / \mathrm{ml})$, and glutamine ( $2 \mathrm{mM})$. 
Islet transplantation. Under Nembutal anesthesia (Dodge Laboratories, Fort Dodge, IA), the portal vein technique (13) was used for the injection of $25 \mathrm{WF}$ islets into the diabetic recipients. The islets had been cultured for $7 \mathrm{~d}$ at $24^{\circ} \mathrm{C}$ before transplantation. Rabbit RALS $(0.2 \mathrm{ml})$ and rabbit MALS $(0.2 \mathrm{ml})$ (Accurate Chemical \& Scientific Corp., Westbury, NY) were injected intravenously via the tail vein into the appropriate recipients 3-4 h before intrahepatic islet preimmunization. The intravenous route was used since the hemagglutinating properties of the ALS results in portal vein thrombosis after islet implantation if administered intraperitoneally. $3 \mathrm{wk}$ after preimmunization, $150 \mathrm{WF}$ islets, cultured overnight at $37^{\circ} \mathrm{C}$, were transplanted under the KC.

Two groups of diabetic mice received $\mathrm{KC}$ transplants of freshly isolated WF islets without intrahepatic preimmunization: group 1 without MALS and RALS; group 2 received a single injection of MALS and RALS, and $21 \mathrm{~d}$ later fresh WF islets were transplanted under the KC. Another two groups of diabetic mice received intrahepatic preimmunization with $25 \mathrm{WF}$ islets that had been cultured for $7 \mathrm{~d}$ at $24^{\circ} \mathrm{C}$ and $21 \mathrm{~d}$ later, 150 fresh WF islets were transplanted under the $\mathrm{KC}$; in group 3 no ALS was given at the time of preimmunization with 25 islets, and in group 4 MALS and RALS $(0.2 \mathrm{ml}$ each $)$ were injected intravenously at the time of preimmunization.

Criteria for rejection. Nonfasting plasma glucose levels were determined three times weekly for $1 \mathrm{wk}$ after the induction of diabetes, for $21 \mathrm{~d}$ after the intrahepatic preimmunization and MALS and RALS administration, and for $60 \mathrm{~d}$ after transplantation of the islets under the KC. Rejection of islet xenografts was considered to have occurred when the plasma glucose concentration exceeded $200 \mathrm{mg} \%$ on two consecutive bleedings. A nephrectomy was done on all of the recipients still normoglycemic at $60 \mathrm{~d}$ after transplantation to be certain that the normoglycemia was due to the islet xenografts in the kidney. Morphologic studies were performed on the liver and kidney of the recipients rejecting the grafts and on the nephrectomized kidney in those recipients still normoglycemic at $60 \mathrm{~d}$. The tissues were fixed in Bouin's solution and stained with hematoxylin and eosin and aldehyde fuchsin (14) to identify beta cells and to assess beta granulation.

Statistics. Individual islet survival is presented and was evaluated for statistical significance by the Kruskal-Wallis nonparametric ANOVA test. Differences were considered significant at $P<0.05$.

\section{Results}

Effect of intrahepatic preimmunization on rat islet xenograft survival. As shown in Table I, freshly isolated WF rat islet xenografts were rejected in an acute fashion when transplanted beneath the $\mathrm{KC}$ of diabetic recipients that did not receive either MALS and RALS or intrahepatic preimmunization with cultured rat islets (group 1, mean survival time [MST] 16.5 \pm 2.5 d). A single injection of MALS and RALS, $21 \mathrm{~d}$ before trans- plantation of fresh WF islets under the KC (group 2) prolonged survival of the xenografts (MST $>32.6 \pm 5.4 \mathrm{~d}$ ) with one recipient still normoglycemic at $60 \mathrm{~d}$. The prolongation of survival was not significant as compared with group 1 because of the wide variation in the survival times. Apparently, the single injection of MALS and RALS 3 wk before transplantation still had some immunosuppressive effect on the survival of the xenografts.

The next question was to determine whether preimmunization with $25 \mathrm{WF}$, low temperature, cultured islets injected into the portal vein would accelerate rejection or prolong survival of the islet xenografts transplanted under the KC $21 \mathrm{~d}$ after preimmunization. As shown in Table I (group 3), slight acceleration of rejection occurred in this group with survival times of 2-13 d (MST 9.5 $\pm 1.8 \mathrm{~d}$ ) as compared with controls (group 1) with a range of 14-34 $\mathrm{d}$ (MST $16.5 \pm 2.5 \mathrm{~d}$ ). Three of the recipients died on days 3,18 , and 18 after preimmunization. Death of these recipients was probably due to the severity of the diabetic state during the preimmunization interval. Bleeding from the site of injection in the portal vein or portal vein thrombosis would have caused death within $24 \mathrm{~h}$ after injection of the islets.

The remarkable finding was that intrahepatic preimmunization with 25 cultured WF islets and a single injection of MALS and RALS completely prevented rejection of the fresh WF islets transplanted under the KC 3 wk after the preimmunization regimen. All 13 of the recipients were still normoglycemic at $60 \mathrm{~d}$ after the $\mathrm{KC}$ transplant (Table I, group 4). The plasma glucose levels in this group are shown in Fig. 1. The recipients remained hyperglycemic during the 3-wk interval after preimmunization with the 25 islets and rapidly became normoglycemic when 150 fresh islets were transplanted beneath the KC. At $60 \mathrm{~d}$ after transplantation, the kidneys were removed bearing the grafts, and the recipients became hyperglycemic again, indicating that the normoglycemia was being maintained by the $\mathrm{KC}$ grafts (Fig. 1). Histologic examination of the islets in the $\mathrm{KC}$ revealed intact islet cells, and the beta cells had a normal degree of beta granulation. Lymphocytes were present around the grafts but not infiltrating them, which is a characteristic finding with established rat islet xenografts in mice $(1,2,6)$.

\section{Discussion}

This study demonstrates that immune unresponsiveness can be induced within $3 \mathrm{wk}$ after intrahepatic preimmunization

Table I. Effect of Intrahepatic Preimmunization with WF Islets and a Single Injection of MALS and RALS on Survival of WF Islet Xenografts under KC of Diabetic C57BL/6 Mice

\begin{tabular}{|c|c|c|c|c|c|c|}
\hline \multirow[b]{2}{*}{ Group } & \multicolumn{3}{|c|}{ Intrahepatic preimmunization (day 21 ) } & \multicolumn{3}{|c|}{$\begin{array}{c}\text { KC transplant (day 0) } \\
150 \text { WF Islets (overnight, } 37^{\circ} \mathrm{C} \text { ) }\end{array}$} \\
\hline & $\begin{array}{l}25 \mathrm{WF} \text { islets } \\
\left(24^{\circ} \mathrm{C}, 7 \mathrm{~d}\right)\end{array}$ & $\begin{array}{l}\text { Site } \\
\text { Liver }\end{array}$ & $\begin{array}{l}\operatorname{RALS}(0.2 \mathrm{ml}) \\
\operatorname{MALS}(0.2 \mathrm{ml})\end{array}$ & Individual survival & Mean \pm SEM & $\begin{array}{c}\text { Survival } \\
\text { (60 d) }\end{array}$ \\
\hline & & & & $d$ & & $\%$ \\
\hline 1 & - & - & - & $14 \times 7,34$ & $16.5 \pm 2.5$ & 0 \\
\hline 2 & - & - & + & $14,19 \times 3,23,26,43,47,56,>60$ & $>32.6 \pm 5.4$ & 10 \\
\hline 3 & + & + & - & $2^{*}, 6,7,10,13 \times 13$ & $9.1 \pm 1.6$ & 0 \\
\hline 4 & + & + & + & $>60 \times 13$ & $>60.0 \pm 0$ & 100 \\
\hline
\end{tabular}

* Three mice died during the $21-\mathrm{d}$ interval between intrahepatic preimmunization and the KC transplants. 


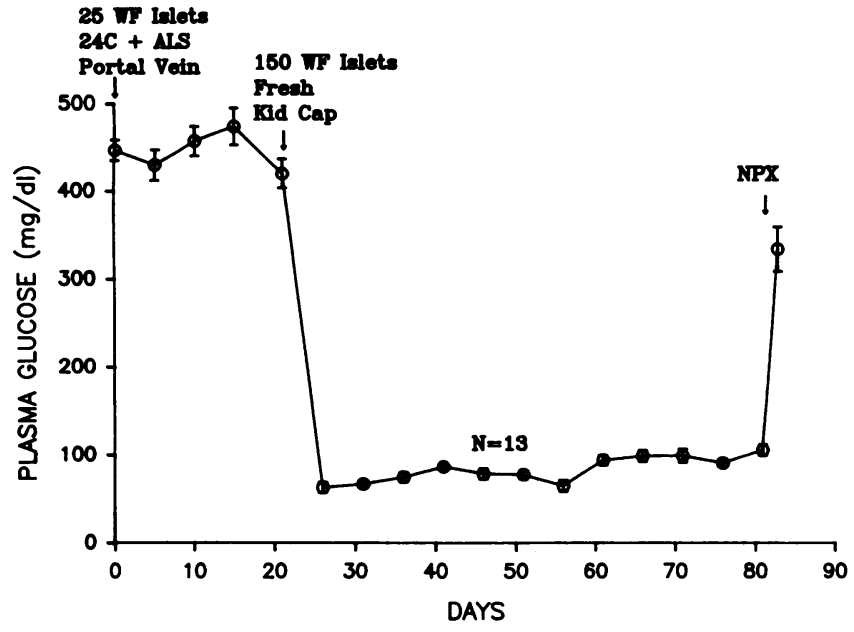

Figure 1. Nonfasting plasma glucose levels $( \pm$ SEM $)$ in diabetic recipient mice (C57/BL6) after KC transplantation of freshly isolated WF rat islets. The preimmunizing WF rat islets were maintained in vitro at $24^{\circ} \mathrm{C}$ for $7 \mathrm{~d}$ before implantation into the liver via the portal vein. All mice received a single injection of MALS $(0.2 \mathrm{ml})$ and RALS $(0.2 \mathrm{ml})$ at the time of implantation. After $60 \mathrm{~d}$ of normoglycemia, all mice were nephrectomized $(N P X)$ to document xenograft function. The individual values for days of normoglycemia are shown in Table I.

with a small number of cultured rat islets (25) and a single injection of MALS and RALS. Rejection of 150 fresh rat islets transplanted under the $\mathrm{KC}$ at 3 wk after preimmunization was prevented in all of the recipients with maintenance of normoglycemia for $>60 \mathrm{~d}$, whereas controls, without preimmunization, had an MST of $16.5 \pm 2.5 \mathrm{~d}$. The single injection of MALS and RALS was apparently required since preimmunization with 25 cultured islets alone in the liver produced a slight acceleration of rejection of the subsequent graft of fresh islets under the $\mathrm{KC}$.

The immunologic mechanisms responsible for the induction of immune unresponsiveness in the intrahepatic site are unknown. Posselt et al. (5) have shown that intrathymic transplants of rat islet allografts with a concurrent, single injection of RALS will produce indefinite survival of the allografts and induction of immune unresponsiveness. They have postulated that ALS depletes peripheral T lymphocytes, prothymocytes now mature in the thymus, and the presence of donor alloantigen in the thymus leads to deletion or inactivation of alloreactive clones. We found recently that indefinite survival and induction of concordant islet xenograft immune unresponsiveness could be induced in mice by intrathymic or intrahepatic transplantation of the islets with a single injection of MALS and RALS, whereas the renal subcapsular site would not permit the induction of xenograft immune unresponsiveness (6). Thus, the microenvironment in the liver appears also to be playing a unique role in the induction of immune unresponsiveness to islet xenografts. Previous studies have shown that delivery of antigens to the liver via the portal vein will prevent antibody production (15) and intraportal injection of allogeneic spleen cells prolonged the survival of cardiac and parathyroid allografts (16-18).

In summary, this study demonstrates that immune unresponsiveness can be achieved across a concordant islet xenograft barrier within $3 \mathrm{wk}$ after intrahepatic preimmunization with a small number of donor rat islets and transient immunosuppression with ALS. These studies may be of importance to clinical islet transplantation since intrahepatic transplants of cryopreserved human islets have been used successfully for achievement of normoglycemia in immunosuppressed patients. This would make it possible to preimmunize with a small number of pure cryopreserved islets and appropriate temporary immunosuppression. Studies are in progress using this preimmunization regimen to determine whether tolerance can be produced to islet allografts in rats and in dogs before considering this approach for human application.

\section{Acknowledgments}

We thank L. McClendon, M. L. Chivetta, P. Bittner, and J. McDonough for technical assistance, and Susan Johnson for preparing the manuscript.

This work was supported by National Research Service Award AI08717 and grant R01 DK 01226 from the National Institutes of Health.

\section{References}

1. Lacy, P. E., J. M. Davie, and E. H. Finke. 1979. Prolongation of islet allograft survival following in vitro culture $\left(24^{\circ} \mathrm{C}\right)$ and a single injection of ALS. Science (Wash. DC). 203:312-313.

2. Lacy, P. E., J. M. Davie, and E. H. Finke. 1979. Induction of rejection of successful allografts of rat islets by donor peritoneal exudate cells. Transplantation (Baltimore). 28:415-420.

3. Lacy, P. E., J. M. Davie, and E. H. Finke. 1980. Prolongation of islet xenograft survival without continuous immunosuppression. Science (Wash. DC). 209:283-285.

4. Lacy, P. E., and E. H. Finke. 1991. Activation of intraislet lymphoid cells causes destruction of islet cells. Am. J. Pathol. 138:1183-1190.

5. Posselt, A. M., C. F. Barker, J. A. Tomaszewski, J. F. Markmann, M. A. Choti, and A. Naji. 1990. Induction of donor-specific unresponsiveness by intrathymic islet transplantation. Science (Wash. DC). 249:1293-1295.

6. Goss, J. A., Y. Nakafusa, E. H. Finke, M. W. Flye, and P. E. Lacy. 1994. Induction of tolerance to islet xenografts in a concordant rat-to-mouse model. Diabetes. 43:16-23.

7. Scharp, D. W., P. E. Lacy, J. V. Santiago, C. S. McCullough, L. G. Weide, L. Falqui, P. Marchetti, R. L. Gingerich, A. S. Jaffe, P. E. Cryer et al. 1990. Insulin independence after islet transplantation into type I diabetic patient. Diabetes. 39:515-518.

8. Warnock, G. L., N. M. Kneteman, E. Ryan, R. E. A. Seelis, A. Rabinovitch, and R. V. Rajotte. 1991. Normoglycemia after transplantation of freshly isolated and cryopreserved pancreatic islets in type I (insulin-dependent) diabetes mellitus. Diabetologia. 34:55-58.

9. Lacy, P. E., and M. Kostianovsky. 1967. Method for the isolation of the intact islets of Langerhans from the rat pancreas. Diabetes. 16:35-39.

10. Lacy, P. E., M. M. Walker, and C. J. Fink. 1972. Perifusion of isolated rat islets in vivo. The participation of the microtubular system in the biphasic release of insulin. Diabetes. 21:987-998.

11. Lindall, A., M. Steffes, and R. Sorenson. 1969. Immunoassayable insulin content of subcellular fractions of rat islets. Endocrinology. 84:218-223.

12. Finke, E. H., P. E. Lacy, and J. Ono. 1979. Use of a reflected green light for specific in vitro identification of islets following collagenase isolation. Diabetes. 28:612-613.

13. Kemp, C., M. J. Knight, D. W. Scharp, W. F. Ballinger, and P. E. Lacy. 1973. Effect of transplantation site on the results of pancreatic islet isografts in diabetic rats. Diabetologia. 9:486-492.

14. Gomori, G. 1950. Aldehyde fuchsin: a new stain for elastic tissue. Am. J. Clin. Pathol. 20:665-670.

15. Trigger, D. R., M. H. Cynamon, and R. Wright. 1973. Studies on hepatic uptake of antigen. I. Comparison of inferior vena cava and portal vein routes of immunization. Immunology. 25:941-950.

16. Rao, V. K., D. E. Burris, S. M. Gruel, H. W. Sollinger, and W. J. Burlingham. 1988. Evidence that donor spleen cells administered through the portal vein prolong the survival of cardiac allografts in rats. Transplantation (Baltimore). 45:1145-1146.

17. Kenick, S., R. P. Lowry, R. D. C. Forbes, and R. Lisbona. 1987. Prolonged cardiac allograft survival following portal venous inoculation of allogeneic cells: what is "hepatic tolerance"? Transplant. Proc. 19:478-480.

18. Kamei, T., M. P. Callery, and M. W. Flye. 1989. Intravenous and portal venous administration of modified donor antigen prolongs rat parathyroid survival. Surgery (St. Louis). 106:1028-1034. 